\title{
Management of Traumatic Brain Injury in Pregnancy: Simultaneous Craniectomy and Cesarean Section Surgeries
}

\author{
Edgar Gomez-Rhenals ${ }^{1} \quad$ Md Moshiur Rahman $2, \odot$ \\ William Florez ${ }^{4, \odot} \quad$ Amit Agrawal ${ }^{5, \odot}$ \\ ${ }^{1}$ Department of Gynecology and Obstetrics, University of Sinu \\ Cartagena de Indias, Bolivar, Colombia \\ ${ }^{2}$ Department of Neurosurgery, Holy Family Red Crescent Medical \\ College, Dhaka, Bangladesh \\ ${ }^{3}$ Center for Biomedical Research, Faculty of Medicine, University of \\ Cartagena, Cartagena, Colombia \\ ${ }^{4}$ Latin American Council of Neurocritical Care, Cartagena, Colombia \\ ${ }^{5}$ Department of Neurosurgery, All India Institute of Medical \\ Sciences, Bhopal, Madhya Pradesh, India
}

Indian J Neurotrauma 2021;18:146-147.

Trauma is one of the main causes of nonpregnancy-related maternal death and it is related with antagonistic fetal outcomes. About 7 to $8 \%$ of all pregnancies are affected by trauma. ${ }^{1} \mathrm{~A}$ life-saving neurosurgical mediation to treat raised intracranial pressing factor is decompressive craniectomy. Basic signs are in the administration of severe traumatic brain injury (TBI).

Recently, a study by Choy and Burns ${ }^{2}$ shared their experience to successful simultaneous decompressive craniectomy and cesarean section. Simultaneous management of concurrent lesions needs a multidisciplinary approach, optimization of the physiology of the mother and fetus, ${ }^{4}$ control of intracranial pressure, and an informed decision whether to deliver the baby first or perform craniotomy first. ${ }^{2-4} \mathrm{~A}$ study showed a case of TBI happening in a term pregnant lady who went through concurrent cesarean delivery and neurosurgery under general anesthesia. ${ }^{3}$ However, just to emphasize primary goal in the management of trauma during pregnancy is focused on optimal maternal resuscitation and early fetal assessment. ${ }^{5}$ If there is rapid neurological deterioration evacuating the intracranial mass lesion becomes the priority to safeguard both mother as well as fetus, ${ }^{2}$ but if there are
Address for correspondence Md Moshiur Rahman, MD, Department of Neurosurgery, Holy Family Red Crescent Medical College, Dhaka 1000, Bangladesh (e-mail: dr.tutul@yahoo.com).

signs of fetal distress and the mother is neurologically stable, caesarean section may be given a priority to deliver the baby. ${ }^{3}$ Further, if the fetus is stable performing craniotomy first may give an option of the vaginal delivery, of course there should not be any signs of fetal distress. ${ }^{3,6}$

It is always a challenge to simultaneously manage the intracranial pathology and safe management of mother and delivery of the baby and require individualized approach (details regarding type of injury, extent of injury, maternal status, gestational age, and status of fetal well-being). ${ }^{3,4}$ A report contributes to decreasing the mortality in women with preeclampsia, given that neurological complications increase mortality rates, ${ }^{7}$ even more before 34 weeks of gestation. ${ }^{8}$ It is important to highlight that puerperium is a procoagulant state and should be carefully surveilled to manage an additional complication in these cases. ${ }^{9}$ Despite cesarean section is the standard treatment for preeclampsia, it should be outlined that it increases the risk of cerebral venous sinus thrombosis (CVST).$^{9}$ There are a couple of cases in the advanced literature observing the utilization of decompressive craniectomy in pregnancy-related CVST; however, in these cases, there was risk factor. ${ }^{10,11}$ published online April 15, 2021
DOI https://doi.org/

$10.1055 / \mathrm{s}-0041-1727405$ ISSN 0973-0508 (c)2021. Neurotrauma Society of India.

This is an open access article published by Thieme under the terms of the Creative Commons Attribution-NonDerivative-NonCommercial-License, permitting copying and reproduction so long as the original work is given appropriate credit. Contents may not be used for commercial purposes, or adapted, remixed, transformed or built upon. (https://creativecommons.org/licenses/by-nc-nd/4.0/).

Thieme Medical and Scientific Publishers Pvt. Ltd. A-12, 2nd Floor, Sector 2, Noida-201301 UP, India 


\section{Conflict of Interest}

None declared.

\section{References}

1 Mendez-Figueroa H, Dahlke JD, Vrees RA, Rouse DJ. Trauma in pregnancy: an updated systematic review. Am J Obstet Gynecol 2013;209(1):1-10

2 Choy B, Burns K. Simultaneous decompressive craniectomy and caesarean section. Br J Neurosurg 2020:1-2

3 Tawfik MM, Badran BA, Eisa AA, Barakat RI. Simultaneous cesarean delivery and craniotomy in a term pregnant patient with traumatic brain injury. Saudi J Anaesth 2015;9(2):207-210

4 Chang L, Looi-Lyons L, Bartosik L, Tindal S. Anesthesia for cesarean section in two patients with brain tumours. Can J Anaesth 1999;46(1):61-65

5 Barraco RD, Chiu WC, Clancy TV, et al; EAST Practice Management Guidelines Work Group. Practice management guidelines for the diagnosis and management of injury in the pregnant patient: the EAST Practice Management Guidelines Work Group. J Trauma 2010;69(1):211-214
6 Gioti I, Faropoulos K, Picolas C, Lambrou MA. Decompressive craniectomy in cerebral venous sinus thrombosis during pregnancy: a case report. Acta Neurochir (Wien) 2019; 161(7):1349-1352

7 MacKay AP, Berg CJ, Atrash HK. Pregnancy-related mortality from preeclampsia and eclampsia. Obstet Gynecol 2001;97(4):533-538

8 Mongraw-Chaffin ML, Cirillo PM, Cohn BA. Preeclampsia and cardiovascular disease death: prospective evidence from the child health and development studies cohort. Hypertension 2010;56(1):166-171

9 Kamel H, Navi BB, Sriram N, Hovsepian DA, Devereux RB, Elkind MSV. Risk of a thrombotic event after the 6-week postpartum period. N Engl J Med 2014;370(14):1307-1315

10 Han KH, Won YD, Na MK, et al. Postpartum superior sagittal sinus thrombosis: a case report. Korean J Neurotrauma 2018;14(2):146-149

11 Kashkoush AI, Ma H, Agarwal N, et al. Cerebral venous sinus thrombosis in pregnancy and puerperium: a pooled, systematic review. J Clin Neurosci 2017;39:9-15 